6. HISTORIA DE LOS DERECHOS PATRIOS IBEROAMERICANO 

Revista de Estudios Histórico-Jurídicos

[Sección Historia de los Derechos Patrios Iberoamericano

XXXIV (Valparaíso, Chile, 2012)

[pp. $407-427$ ]

\title{
CÁdiz en Charcas: CONJeTURAS E INDiCiOS
}

[Cadiz in Charcas: Conjectures and Indications]

\author{
Horacio Andaluz Vegacenteno* \\ Universidad Privada de Santa Cruz de la Sierra, Bolivia
}

\section{RESUMEN}

Este es un artículo de historia constitucional. Se centra en la relación entre la Constitución española de 1812 y la Constitución boliviana de 1826 . Su conclusión principal niega la idea de que, porque ambas fueron cartas liberales, la primera Constitución haya influenciado a la segunda.

\section{Palabras clave}

Constitución de Cádiz - Constitución de Bolivia de 1826 - Constitucionalismo bolivariano.

\section{AbSTRACT}

This article deals with constitutional history. It focuses on the relationship between the Spanish Constitution of 1812 and the Bolivian Constitution of 1826. Its main conclusion rejects the idea that, because both of them were liberal constitutions, the former Constitution influenced the latter.

\section{KEYwORDS}

Constitution of Cadiz - Constitution of Bolivia of 1826 - Bolivarian Constitutionalism.

ReCibido el 19 de diciembre de 2011 y aCEPTADo el 2 de junio de 2012

* Profesor de Derecho de la Universidad Privada de Santa Cruz de la Sierra (Bolivia). Domicilio postal: Casilla Postal 4710, Santa Cruz de la Sierra, Bolivia. Correo electrónico: handaluz@post.harvard.edu 
A comienzos del siglo XIX había sólo tres constituciones liberales: estaba la de los Estados Unidos, que fue la primera, de 1787; la segunda fue la francesa, de 1791; y la tercera fue la española, la Constitución llamada de Cádiz, de 1812. Esta última instauraba una monarquía constitucional, regida por la separación de poderes, el sufragio universal y la soberanía nacional. Pero su duración fue efímera y su eficacia nominal. Entró en vigor el 19 de marzo de 1812 y dejó de estarlo el 4 de mayo de 1814, cuando Fernando VII la derogó por decreto, a ella y a todas las disposiciones producidas para su desarrollo. Luego el mismo Fernando VII la juró en 1820 y estuvo en vigor hasta 1823, cuando la Santa Alianza lo repuso en el Absolutismo. Recobró vigencia una última vez entre 1836 y 1837, como preludio a la Constitución de aquel último año.

En los mismos tiempos, la Real Audiencia de Charcas, de la que nació Bolivia, se enrumbaba hacia su independencia. El período entre 1809 y 1825 fue de lucha. La separación definitiva de la metrópoli se declaró este último año; el texto original de la Constitución viene de 1826. Fue por igual una norma de cuño liberal, que inauguró un gobierno republicano de poderes limitados. Coincide con Cádiz en el tiempo, la lengua y la ideología. ¿Quiere decir esto que estuvo influenciada por aquella? Conjeturo que no: i) Se trata de dos manifestaciones de un mismo producto cultural (el constitucionalismo liberal decimonónico); en consecuencia, por fuerza debían coincidir. Esto no es de extrañar. Es la confirmación de que se trata de dos criaturas engendradas por el mismo pensamiento: aquel que dio consistencia ideológica al momentum liberal, primero en Estados Unidos, después en Francia, luego, como accidente, en España, y, finalmente, en las colonias hispanas en América. ii) Las coincidencias no significan influencia. La influencia necesita de una relación de autoridad moralmente justificada, que fundamente la decisión del agente, consciente o inconscientemente influenciado, de emular su modelo de referencia. Y esto es lo que verosímilmente faltaba entre Cádiz y Charcas. Si la de Cádiz era la Constitución del poder metropolitano contra el que la insurgencia justificaba su lucha, ¿es verosímil que el pensamiento de los mismos insurgentes, ganada la independencia, reconociese autoridad a una norma de cuna metropolitana que convertía en españoles a quienes renegaban de España (artículo 1)? A mi juicio no.

Racionalmente, la pretensión de Cádiz era perfectamente opuesta a la pretensión independentista. Esto ya autoriza a asumir que no podía provocar sino un rechazo de plano. Objetivamente, se trataba del acto definitivo de conquista: la equiparación política de las colonias a la metrópoli no es otra cosa que la absorción sellada y lacrada. Aquí lo verosímil es la férrea oposición; no sólo a tal intento, sino al designio de atar el destino de América a los dictados ibéricos. No es casual el siguiente párrafo del "Discurso pronunciado el 3 de julio de 1811 en la Sociedad Patriótica de Caracas, por el coronel Simón Bolívar”: “¿Yqué dicen? [...] Que debemos atender a los resultados de la política de España. ¿Qué nos importa que España venda a Bonaparte sus esclavos o que los conserve, si estamos resueltos a 


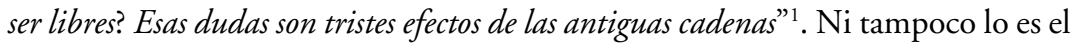
texto de pasquines como los "Reparos al anónimo que se indica", que circulaban por Charcas por agosto y septiembre de 1809: "[Ante el temor de ser franceses o portugueses, e incluso ingleses], no le queda a la América otro recurso, ni otro término que el de governarse por sí misma. Más vale morir porque Reyne la Patria, que morir porque otro reyne sobre ella haciéndola esclaba y tributaria sin medida. Si la América puede pelear a favor de extraños, es regular que conosca, que la es mejor pelear para sí; que es decir para el bien del Pueblo"2.

$\mathrm{Y}$, emocionalmente, lo verosímil es lo contrario: el fragor de la gesta independentista habría quitado oídos a todo lo que viniese de la antigua metrópoli, no obstante bueno o conveniente. Este es un buen ejemplo: cuando el mariscal Sucre pidió al Congreso de 1826, que fue el encargado de aprobar el texto original de la Constitución, que diese al teniente coronel español Facundo Infante el grado de coronel de Bolivia, presumiblemente José María Bozo, diputado por Santa Cruz, dijo: "Señor Presidente: acabamos de libertarnos del León de Iberia y veo por esta propuesta que se trata de crear cachorritos en Bolivia. Me opongo a esa propuesta" . Bozo, si fue él, no era hombre de pensamiento improvisado, aunque sí de extravagancias. Naturalista, filósofo, magistrado y profesor, se recibió de abogado en 1806 y recibió las órdenes menores en $1807^{4}$. Tenía la formación y entereza suficiente para no sucumbir a patriotismos de plazoleta. Pero de nada le habría valido que Infante hubiese dirigido la oposición al absolutismo de Fernando VII, y sido diputado y secretario de las Cortes durante el trienio liberal de 1821 a $1823^{5}$. Y tampoco que hubiese ejercido una "decisiva influencia" liberal en las presidencias de Bolívar y Sucre, "primero como secretario y después como ministro", tanto que "la política en general y muy especialmente la instrucción pública lleva[n] [su] sello liberal" ". Ninguna de estas credenciales habría podido más en el juicio de Bozo que el accidente del lugar de nacimiento de Infante.

En resumen, sustento la opinión de que hay más razones para negar la influencia de Cádiz en Charcas, que para afirmarla.

Esto es una conjetura. Pero muchos indicios llevan a ella.

II.

En 1808, tras las abdicaciones sucesivas de Carlos IV y Fernando VII a favor de Napoleón, y la cesión de éste del trono español a su hermano José, se formaron

${ }^{1}$ En Itinerario documental de Simón Bolivar, Escritos selectos (Caracas, Ediciones de la Presidencia, 1970), p. 27.

${ }^{2}$ Cit. por Just Lleó, Estanislao, Comienzo de la independencia en el Alto Perú. Los sucesos de Chuquisaca, 1809 (Sucre, Editorial Judicial, 1994), p. 404.

${ }^{3}$ Cit. por VÁzQUez Machicado, Humberto, Evolución de las ideas y los partidos políticos en Bolivia, en Obras Completas (La Paz, Don Bosco, 1988), VII, p. 335. 58.

${ }^{4}$ Pérez Fernández, Marcelino, Pensadores cruceños (Santa Cruz, UPSA, 1992), pp. $27-$

${ }^{5}$ Barnadas, Joseph M. para el Diccionario histórico de Bolivia (Sucre, Grupo de Estudios Históricos, 2002), I, p. 1070.

${ }^{6}$ Vázquez Machicado, H., cit. (n. 3), p. 333. 
en distintos lugares de España unas juntas de gobierno que pretendían gobernar en nombre del rey depuesto y preservar sus derechos al trono. Paralelamente, el 25 de mayo de 1809 se produjo en Chuquisaca un levantamiento contra el gobernador intendente de Charcas, destituyéndolo y formando también una junta de gobierno en su reemplazo.

La invasión napoleónica fue el momento propicio para, aparentando fidelidad a Fernando VII, plantear la independencia. Y si este fue el planteamiento, las Cortes de Cádiz y su producto, la Constitución, no habrían de convocar la simpatía de los independentistas. De la fidelidad sólo aparente al rey se convencería por su propia cuenta el mariscal de campo Vicente Nieto, venido a Charcas con el título de presidente de la Audiencia. Había sido enviado por Baltasar Hidalgo de Cisneros, virrey de Buenos Aires, para pacificar Chuquisaca tras su levantamiento. Llegó a su destino el 25 de diciembre de 1809. El 25 de mayo de 1810 el virrey Cisneros y el gobierno español fueron depuestos por la rebelión que estalló en Buenos Aires. Esto pronto se supo en la Audiencia de Charcas. Allí Nieto recibió un pasquín fechado en "Cochabamba y agosto 15 de 1810", que, según Humberto Vázquez Machicado, habría sido deliberadamente escrito con errores de redacción y ortografía para eludir la persecución realista, y aludiría a Francisco de Paula Sanz, gobernador intendente de Potosí, José González de Prada, gobernador de Cochabamba, Jerónimo de Marrón y Lombera, comandante de armas del mismo sitio, y al propio Nieto, que sería el "cojo fanfarrón” al que se dirigía el pasquín, aunque esto es una suposición que Vázquez Machicado halla verosímil por haber participado Nieto en las campañas de los Pirineos y Cataluña ${ }^{7}$.

A continuación el texto; pero repárese: $i$ ) en el lenguaje con el que despectivamente se refieren a España; y ii) en la abierta provocación a la autoridad ultramarina que encierra la frase "quedaremos todos en pazy quietud, bibiendo una vida tranquila entre puros Criollos, quedando el mando en ellos como buenos republicanos". Dice el texto: "Mira cojo fanfarron; tu piensas de que nosotros ignoramos de que el Rey fernando no esta ya en la sepultura con toda la casa de Borbon? Bosotros sois los que quereis hacerte Reyes, el pipon de Paula Sanz, un gran mentecato, tu cojo patituerto, pati sambo, patuleco, pati demonio, Prada cara de Judas, hipocritán, traidor, y Lombera cara de chibato lujurioso, que como saben que el Porteño biene barriendo a todos los españoles Chapetones dandoles en la cabeza, o embarcandolos y discurriendo que con bosotros ha de correr la mesma fortuna, se apresuran a juntar gente para contra restar al porteño que biene a sacudir el Yugo y quitarnos la carga de ensima de nuestros hombros y librarnos de la esclavitud de un pirata como el español [...]. Las maximas con que bosotros os manejais bien las conocemos y penetramos con mucho sentido y si hasta aqui hemos handado sumisos y prudentes sin negarte la obediencia, hacido para segurar mejor el golpe, que bais a sufrir bosotros en brebe, y esta es la mejor ocacion, la mas proporcionada, adecuada, y excelente, que quitadas estas malillas, sesaran las bullas y quedaremos todos en paz y quietud, bibiendo una vida tranquila entre puros Criollos, quedando el mando en ellos como buenos republicanos [...]"8.

${ }^{7}$ VázQuez MachiCado, Humberto, El Pasquismo sedicioso y los prodromos de la emancipación en el Alto Perú, en Obras, cit. (n. 3), III p. 231.

${ }^{8}$ Cit. por Vázquez Machicado, H., cit. (n. 7), pp. 229-230. 
Pues bien, quien anhela su independencia, no quiere ser español. Y, dice Sánchez de Velasco en sus Memorias para la historia de Bolivia desde el año 1808 a 1848, que "desde el momento en que supo la ocupación de España por el ejército del memorable Napoleón, aparecieron en América los sintomas de una convulsión general' '. Y de ello da fe el propio fiscal de la Audiencia de Charcas, don López Andreu, quien escribió al rey: "La situación de la Europa, y particularmente de la Madre-Patria prestó materiales copiosos a los ánimos débiles o propensos a novedades para tomar partido con transgresión de las obligaciones más sagradas, y voló en dirección al camino ambicioso de la combeniencia propia"10.

\section{III.}

En 1812, con ocasión de la promulgación de la Constitución de Cádiz, el virrey Abascal, en Lima, ordenó festejos en todo el territorio del virreinato. En Chuquisaca, el presidente de la Audiencia de Charcas, brigadier Juan Ramírez, "ordenó replique de campanas, salvas de artillería, iluminación general durante tres noches, asi como Tedeum y rogativas" ${ }^{11}$. Y, cuando Fernando VII la juró en 1820, la Constitución de Cádiz fue jurada en los pueblos de Charcas en octubre de aquel mismo año ${ }^{12}$. Los festejos y juramentaciones no habrían tenido mayor repercusión, aparentemente. Se trataba de actos formales, ordenados por el poder español y que conmoverían a los realistas; no de acontecimientos populares.

Sin embargo, quienes activamente preparaban la insurgencia habrían temido los efectos que la factura de Cádiz pudiese tener en sus perspectivas de independencia. Acá el rechazo es manifiesto, como lo muestra un pasquín abocado al desprestigio de las Cortes de Cádiz, que dedica su texto a alegar su invalidez. Vázquez Machicado resume lo que habría pasado por las mentes de sus autores: "como quiera que [la declaración de 16 de octubre de 1810] podría engañar a muchos patriotas y entibiar en ellos el fuego revolucionario, era necesario desprestigiar y presentar como nulas, intrusas e ilegales a las Cortes llamadas de Cádiz"13. Queda clara la intención de negarle oídos a lo que venía de España. La justificación es la oposición de pretensiones entre el proyecto de Cádiz y el de los independentistas.

Las Cortes de Cádiz se formaron a partir de un llamado que hizo el Consejo de Regencia el 14 de febrero de 1810, por el que se convocaba a la elección de diputados. A las provincias españolas les correspondía un diputado por cada cincuenta mil habitantes. A las posesiones en América, en cambio, les tocaba un diputado por cada capital cabeza de partido, no obstante la solemne declaración

\footnotetext{
${ }^{9}$ Cit. por Just LleÓ, Estanislao, cit. (n. 2), p. 364.

${ }^{10}$ Ibíd., p. 365.

${ }^{11}$ Querejazu, Roberto, Historia de Chuquisaca, cit. por Siles Salinas, Jorge, Historia de la Independencia de Bolivia (2a edición, La Paz, Plural, 2009), p. 204.

${ }^{12}$ Mendoza Loza, Gunnar, Monografía de Chuquisaca: historia colonial, historia de la independencia, cultura, en Obras Completas (Sucre, Fundación Cultural del Banco Central de Bolivia/Archivo y Biblioteca Nacionales de Bolivia, 2005), I, p. 262.

${ }^{13}$ VázQuez Machicado, H., cit. (n. 7), p. 233.
} 
que dijo que aquellas "no eran colonias o factorías como las de las otras naciones, sino una parte esencial e integrante de la monarquía española" ${ }^{14}$. Para el 8 de septiembre se dispuso que los emigrados americanos residentes en Cádiz eligieran a 30 diputados por América. Se pensó que éstos fueran suplentes, pero en realidad fueron los "verdaderos representantes" de las colonias, "pues de ellos, lo menos la mitad actuó en las Cortes"15. Las Cortes de Cádiz se instalaron el 24 de septiembre, con 27 representantes americanos: uno era un "diputado propietario americano”, y 26 fueron suplentes. Por la Audiencia de Charcas estaban dos: Mariano Rodríguez Olmedo, presbítero, y Antonio Zuazo, brigadier de los ejércitos reales $^{16}$ (su profesión ya dice, de por sí, de su partido). Para el 16 de octubre las Cortes habían publicado en su Gaceta una declaración concerniente a las colonias americanas. Tenía tres partes. En la primera se ratificaba "el inconcuso concepto de que los dominios españoles en ambos hemisferios forman una misma y sola monarquí, una misma y sola Nación y una sola familia, y que por lo mismo los naturales que sean originarios de dichos dominios europeos o ultramarinos son iguales en derechos a los de la península". La segunda decía: "quedaba a cargo de las Cortes tratar con oportunidad y con particular interés todo cuanto pudiera contribuir a la felicidad de los de Ultramar, como también del número y forma que debiera tener en lo sucesivo la representación nacional en ambos hemisferios". Y, la tercera expresaba: "que desde el momento en que los paises de Ultramar en donde se hubieran manifestado conmociones hicieran el debido reconocimiento a la legitima autoridad soberana que se haya establecido en la madre Patria, hubiera un general olvido de cuanto hubiese ocurrido indebidamente en ellos, dejando, sin embargo, a salvo, el derecho de terceros" ${ }^{17}$.

Fue contra esta declaración que la vanguardia independentista reaccionó con el escrito que se tituló de Razones en que se apoya el desconocimiento de las Cortes y su absoluta nulidad. Las razones aducidas se dirigían contra la convocatoria a las Cortes en sí misma, el desproporcionado número de representantes americanos en relación a los peninsulares y la falta de representación política de los diputados que obraban por las colonias sin haber sido elegidas por ellas. Con esto mostraban a las Cortes como el ejercicio de autoridad de un poder foráneo, intruso en los intereses americanos, que a la fuerza quería hacerles seguir su mismo destino. Y, nótese en la decimoprimera razón del pasquín, el claro objetivo de que las colonias no sigan la suerte de su metrópoli ("Este Reyno separó su gobierno de Europa”).

He aquí el texto: "1a.- La convocatoria a Cortes es privativa del Soberano, según la ley: la Regencia no es ni ha podido ser el soberano: luego no pudo convocar a las Cortes. $2^{\mathrm{a}}$-- Las Cortes convocadas por una autoridad ilegitima, son ilegitimas: las actuales Cortes convocadas por la Regencia, que es una autoridad intrusa e ilegitima (como se ha demostrado hasta la evidencia): luego las actuales cortes son intrusas e ilegitimas. $3^{a}$.- Las Cortes han nombrado Diputados a razón de uno por cien mil almas: es asi que no se ha guardado con igualdad este Censo: luego no hay Cortes. $4^{\mathrm{a}}$.- Tres millones

\footnotetext{
${ }^{14}$ Ibíd., p. 232.

${ }^{15}$ Ibíd., p. 232.

${ }^{16}$ Tredinnick Abasto, Felipe, La revolucionaria Constitución de Cádiz de 1812, en Revista del Tribunal Constitucional, 3 (2000), p. 75.

${ }^{17}$ Cit. por VázQuez Machicado, H., cit. (n. 7), p. 232.
} 
de hombres deben ir a las Cortes para que sean legitimos 60 representantes: el Reyno de Santa Fe tiene tres millones de hombres: luego para que las Cortes fuesen legitimas debian dar al nuebo Reyno 60 representantes; es asi que no han puesto mas que tres en lugar de 60: luego las Cortes son nulas. 5ª.- Para que las Cortes fuesen legitimas cada cincuenta mil almas según lo sancionado, deben dar un representante: es así que la America Española tiene por lo menos doce millones de hombres; luego para que las Cortes fuesen legitimas debia haber en ellas 240, representantes Americanos: es así que no se hallan en ellas sino apenas 27 luego son ilegitimas las Cortes. 6a.- Las Provincias sujetas a José Bonaparte pertenecen a éste por derecho de conquista: es asi que las Probincias sugetas a Bonaparte tienen representantes en las Cortes: luego las Cortes tienen representantes de Bonaparte: es asi que las Cortes en que tiene representación Bonaparte son nulas: luego las actuales Cortes son nulas. $7^{\mathrm{a}}$.- El mayor número de representantes en Cortes, es el que la forma o decide la Votacion; es asi que el mayor número de representantes en las actuales Cortes, es de las provincias conquistadas o adheridas a José: luego los representantes de las Provincias sujetas a José forman las Cortes y deciden la votación: es asi que tales Cortes son nulas, y sólo pueden ser legitimas para los Napoleonistas: luego las tales Cortes son para nosotros ilegitimas. $8^{\mathrm{a}}$ - No puede haber apoderado que no haya recibido poderes e instrucciones del poderdante, es así que los representantes Americanos que están en las Cortes no han recibido poderes, ni instruccion de la América: luego no pueden ser Apoderados ni representantes de ella: es asi que las Cortes donde no hay Apoderados de la América son nulas: luego las actuales Cortes son nulas. 9a.- Para la legitimidad de las Cortes se necesita de libertad: es así que en las actuales Cortes no hay libertad: luego no son legitimas, se aprueba la menor. Por una parte la fuerza francesa, por otra la Inglesa tienen oprimidas las Cortes; por otra parte la voz Americana se halla ahogada con el excesivo número de suplentes de la España Francesa: luego en las actuales Cortes no hay libertad. 10a.- La mayor parte debe arrastrar la menor; es asi que los Americanos españoles, son mayor que los Españoles Europeos: luego la parte Americana debe arrastrar la Europea: es asi que a la mayor compete el convocar las Cortes: luego le compete a la América la convocatoria de las Cortes. $11^{\mathrm{a}}$.- Este Reyno separó su gobierno de Europa porque el Tirano Napoleón iba conquistando la Peninsula y nos exponíamos a ser conquistados con el reconocimiento de la Regencia: es asi que cada dia adelanta sus conquistas y estamos expuestos con el reconocimiento de las Cortes: luego hay motibo para que cada día nos separemos mas $y$ desconozcamos las Cortes con más empeño que la Regencia. 12a.- Las Cortes ofrecen indultos a los Americanos siempre que no haya daño de tercero; es asi que no puede haber caso en que no haya daño de tercero en una revolución: luego no hay caso en que se pueda verificar el indulto: luego el indulto que se ofrece por las Cortes es como el que se les ofreció a los habitantes de La Paz; como el que se ofreció a los quiteños; y como el que se ofreció en presencia del Santísimo Sacramento a los del Socorro, juramentos $e$ indultos que fueron manchados con la sangre americana" 18 .

${ }^{18}$ Ibíd., pp. 233-234. 
IV.

El 16 de julio de 1809 La Paz se alzó en revolución. Igual que como ocurrió en Chuquisaca, allí también se separó de su cargo al gobernador intendente y se formó una junta, la Junta tuitiva de los derechos del rey y del pueblo. Según un documento identificado con el No 13.150 de los manuscritos de la Biblioteca Nacional de Madrid, que estuvo inédito hasta su publicación en 1957 por Vázquez Machicado, lo de tutelar los derechos del rey era una expresión retórica. Esto fue advertido en abundancia por los autores del documento referido, los caballeros Jorge de Ballivián, Benito Blas de la Abariega, Agustín de Álava, Pedro Gonzales Rubín y José de Mendizábal e Imaz, españoles todos y prófugos y refugiados en el "Puerto y Ciudad de San Marcos de Arica", donde suscribieron su relato al virrey de Buenos Aires el 6 de octubre de 1809 . Y no estaban para nada equivocados en su apreciación de los hechos. La Junta lanzó su proclama en La Paz "a los 17 días del mes de julio de 1809" y, respecto a la desgracia de la corona española, sólo exhortaba a aprovechar su caída ("aprovechaos de las circunstancias en que estamos"): "Compatriotas: Hasta aqui hemos tolerado una especie de destierro en el seno mismo de nuestra patria; hemos visto con indiferencia por más de tres siglos sometida nuestra primitiva libertad al despotismo y tirania de un usurpador injusto que, degradándonos en la especie humana, nos ha mirado como esclavos; hemos guardado un silencio bastante parecido a la estupidez que se nos atribuye por el inculto español, sufriendo con tranquilidad que el mérito haya sido siempre un presagio de humillación y ruina. Ya es tiempo, pues, de sacudir yugo tan funesto a nuestra felicidad, como favorable al orgullo nacional español. Ya es tiempo, en fin, de levantar el estandarte de la libertad en estas desgraciadas colonias, adquiridas sin el menor titulo y conservadas con la mayor injusticia y tiranía. Valerosos habitantes de La Paz y de todo el Imperio del Perú, revelad vuestros proyectos para la ejecución; aprovechaos de las circunstancias en que estamos; no miréis con desdén la felicidad de nuestro suelo, ni perdáis jamás de vista la unión que debe reinar en todos, para ser en adelante tan felices como desgraciados hasta el presente" 19 .

En los párrafos que a continuación se transcriben de la "Relación imparcial de los acaecimientos de la ciudad de La Paz en la noche del 16 de julio de 1809 y días sucesivos", título del documento de los caballeros españoles prófugos, préstese atención al fundado sentimiento de indignación de sus suscriptores, que advierten que la defensa de la corona española es tan sólo un enmascaramiento de los afanes independentistas: "Desde el momento en que se supo en La Paz que la introducción de los Ejercitos franceses en el territorio español bajo las apariencias de amistad y buena fe no tuvo otro objeto que el de apoderarse de la Monarquia y que dieron principio a la ejecución de este pérfido e inicuo plan, con la prisión de nuestro idolatrado Rey el Sr. Don Fernando VII, desde ese momento, decimos, tuvieron por inevitable aquella monstruosa usurpación, los cobardes para quienes el Imperio francés habia llegado al mas agigantado poder, y al contrario, la España al ultimo grado de abatimiento

${ }^{19}$ En Trigo, Ciro Félix, Las constituciones de Bolivia (2 ${ }^{\text {a }}$ edición, La Paz, Fondo Editorial de la Biblioteca y Archivo Histórico del Honorable Congreso Nacional, 2003), p. 179. 
y estado de nulidad en el orden politico; [...]. Como a aquel acontecimiento debía seguirse, segun aquellos cobardes, pérfidos, traidores, la independencia de las Americas, empezaron desde luego a formarse en su loca fantasía, imperios, Reinos y Repúblicas y cada uno se contemplaba cuando menos acreedor al Gobierno de una Provincia, idóneo y capaz para el desempeño de un ministerio; [...], resolvieron aprovecharse de este tiempo de turbulencia y aflicción y separarse de la Metrópoli, dejando a la Madre Patria no solo envuelta en sus actuales desgracias, sino también en llorar la separación de su America, mediante a que los autores de la maldad se persuaden de que la España no podrá a un tiempo atender a dos objetos, esto es, a la expulsión de los franceses y al pronto auxilio de gente y expertos Jefes para la conservación de estos dominios. [...] estaban los traidores forjando las supuestas y falsas relaciones que debian por algun tiempo alucinar a los demás Jefes del Reino, no por eso les faltó tiempo para expedir muchas inicuas órdenes y entre ellas la de que los europeos se presentasen en la Plaza Mayor a las tres de la tarde; asi en efecto se hizo y entre la descompasada vocingleria e insultos de infinita plebe profanando con escándalo el retrato de nuestro Augusto y desgraciado Soberano Fernando VII que desde la primera noche se colocó en aquel puesto para solapar y escuchar sus designios, ante el Ilustre Cabildo y en manos de uno de sus Regidores y es D. Juan Bautista Sagarraga conocido y temido siempre por uno de los mayores traidores a la Corona hubimos de hacer juramento uno después de otro y aunque según era nuestra sorpresa no podremos dar razon de su fórmula en el todo tenemos presente ser reducido en lo principal a lo siguiente: Jura $V$. hacer causa comun con los Americanos? Jura $V d$. Ir con sus sistemas y opinión? Jura $V$. no atentar contra sus vidas? Siendo de notar que para encubrir la malicia que encierran en si estos puntos agregaban: Jura V. igualmente ser fiel a Fernando VII? Y de aqui es que el pasaje humillante de exigir juramento de fidelidad al Soberano unos hombres declaradamente enemigos y traidores al Rey a unos hombres fieles y amantes vasallos de tan suspirado Monarca en cuya defensa sacrificarán gustosos sus vidas y haciendas; [...]. [...] réstanos indicar los fines a que todo se dirige y de los cuales estamos impuestos por algunos de los mismos revoltosos con los disparatados términos siguientes: Si los franceses (dicen) dominan la España parece ser consiguiente que alguno de la familia Real se traslade a esta America y establezca su solio en Lima o Buenos Aires, y como de este principio resultaria el engrandecimiento únicamente de la Ciudad donde resida la Corte y absorviendose esta las riquezas de las provincias interiores, nunca estas saldrian del estado de inercia ya abatimiento en que se hallan. Conviene (añaden) suceda o no el caso de la dominación francesa, preparar y disponer los pueblos al intento de que las provincias del Perú se declaren por confederadas independientes y a La Paz por Capital de ellas para que asi obtenga entre las ciudades del mundo el lugar y representación celebre de una Berna"20.

A mayor abundamiento, los autores de la Relación imparcial dieron señales biográficas de los protagonistas de la Junta. Coinciden todos en su vocación independentista. De Pedro Domingo Murillo, su presidente y principal figura de la revolución de La Paz, dijeron que "fue preso por considerarlo autor de unos

${ }^{20}$ Cit. por Vázquez Machicado, H., La Revolución de La Paz en 1809 cit. (n. 7), pp. 269-280. 
pasquines dirigidos a un igual caso al presente”. A Gregorio Lanza, vocal y otro de los principales partícipes en la revolución, lo describieron como persona "con inclinación e ideas de Independencia". De Juan Basilio Catacora, también vocal, se dijo que "en ocasiones ha manifestado sentimientos sanguinarios y revolucionarios". De José Antonio de Medina, que era "inclinado a las ideas de independencia". Y, de Melchor León de la Barra, que era "sedicioso, enemigo declarado de los europeos, juramentado para atentar contra la Corona"21.

De vuelta en Charcas, igual noticia daba el abogado realista Baez, respecto a los hechos ocurridos en la península y los sentimientos solapados que produjeron en la Audiencia: "En esta situación turbulenta - disgustos entre las autoridades ciudadanas por los sucesos del Corpus-, llegaron las primeras noticias de pérfida prisión de nuestro Augusto Soberano el Señor Don Fernando VII con las demás novedades, que derramaron por la América opiniones muy perjudiciales sobre la suerte funesta de la España. Los Ministros que casi todos era hechura de D. Manual Godoy de otros traidores vendidos a Bonaparte tuvieron muy mal el nuevo sistema de nuestro Gobierno, y comenzaron a manifestar a las claras o por enigmas el estado infeliz de nuestra Monarquía, no por desconsuelo de nuestra común desgracia, ni por amor al Rey o adhesiones a la Metrópoli, sino para dispertar en las Américas las ideas de independencia con el pretexto de fidelidad al Señor Don Fernando VII'22.

\section{V.}

El sentido de oportunidad de los independentistas que revelan los indicios anteriores (II a IV) no debe sorprender. Tampoco debe hacerlo el hecho de que el discurso republicano no se hubiese planteado, desde un inicio, en forma abierta y explícita. En sus inicios, la lucha por la independencia se hizo a hurtadillas y con conductas ambiguas. A la vez que se proclama fidelidad a Fernando VII, se constituían juntas que tutelasen los derechos del pueblo en caso de que no retornase al trono.

El siguiente es un Testimonio de fidelidad y amor a nuestro monarca augusto Sr. Don Fernando VII, leído en la Real Academia Carolina de Practicantes Juristas, especie de seminario de dos años de duración para que los candidatos a la abogacía se familiarizaran con la legislación vigente: "Los americanos, los fieles vasallos de la lejana América, acompañan a su caro Rey en la desgracia que sufre, cubiertos de luto y desolados: en el pais del horror y los delitos, donde le detiene oprimido la injusticia, alli le respetan, alli le aman, alli proclaman su soberania; y menospreciando al sacrilego usurpador de sus derechos, a quien no temen ni obedecen de unánime concierto reaniman la lealtad un amor eterno" 23 . Pero mientras este era el discurso público, corría por debajo el siguiente razonamiento, descrito por Gabriel René Moreno ya en 1896, y que llevaba a un solo resultado: la independencia, porque, si el "amado" rey sigue vivo, igual "ya no volverá": "El silogismo con que los doctores hicieron

\footnotetext{
${ }^{21}$ Ibíd., pp. 273, 276 y 277.

${ }^{22}$ Cit. por Just Lleó, Estanislao, cit. (n. 2), p. 365

${ }^{23}$ Cit. por Moreno, Gabriel René, Últimos días coloniales en el Alto Perú (La Paz, Juventud), p. 244.
} 
la revolución altoperuana, y cuya fuerza peripatética hizo saltar a la arena política a todos los audaces de su gremio y a no pocos tímidos incautos fue el siguiente: Mayor: el vasallaje colonial es tributo debido no a España, sino a la persona del legítimo rey borbónico de España; Menor: Es así que nuestro legítimo y recién jurado rey y señor natural don Fernando VII abdicó junto con toda la familia borbónica de España y ya no volverá. Consecuencia: Luego la monarquía está legal y definitivamente acéfala por vacancia del trono, debe ser desobedecido el rey Bonaparte o cualquier otro que España quiera darse, deben cesar en sus funciones los actuales delegados y mandatarios de la extinta autoridad soberana, y deben en este caso proveer por sí mismas las provincias altas a su propio gobierno supremo con calidad por ahora mientras no constare auténticamente la muerte de nuestro amado rey don Fernando VII, y hasta que se presente legítimo sucesor al señorío de estas Américas"24.

\section{VI.}

En 1947 Gunnar Mendoza publicó un artículo que llevó por título: Influencia de la Declaración de Independencia de los Estados Unidos de América en el Acta de Independencia del Alto Perú. Como método, partió por diferenciar las "similitudes y disimilitudes que podemos llamar forzosas o espontáneas", que provienen, respectivamente, "de la analogía general de las situaciones a que responden tales documentos" y "de la diferencia de circunstancias peculiares a uno y otro dentro, no obstante, de la similitud general”, con las "analogías que no pueden ser forzosas desde el momento en que ya no aluden a situaciones generales semejantes" 25 . Comparto su método, en el sentido que está dicho en el punto I. Sometidos ambos textos a su análisis, Mendoza concluyó que había una influencia patente, en lo que hace a analogías no forzosas, de la Declaración americana en el Acta boliviana, aunque era una "influencia más bien fraseológica que ideológica" 26 . Esta fue la prueba que llamó "intelectual"27: "Al hablar de la obra de muerte, desolación y tiranía de Gran Bretaña, la declaración norteamericana señala las 'circumstances of cruelty and perfidy scarcely paralleled in the most barbarous ages', y la declaración altoperuana se refiere a "La sangre de miles de mártires de la patria ultimados con suplicios atroces que estremecerían a los caribes”. Se insinúa aquí un parentesco expresivo entre ambos textos, si bien podría decirse que es apenas un parentesco de cuarto o quinto grado. La afinidad se hace próxima al referirse el texto norteamericano a 'certain unalienable rights, that among these are life, liberty', así como a los conceptos de 'safety' y 'security' en tanto que el texto altoperuano trae a cuento los "sacrosantos derechos de honor, vida, libertad, igualdad, propiedad y seguridad”. El aire de familia es más perceptible en el pasaje donde los norteamericanos proclaman que, al adoptar la independencia, 'a decent respect to

\footnotetext{
${ }^{24}$ Ibíd., p. 385.

${ }^{25}$ Mendoza Loza, Gunnar, Influencia de la Declaración de Independencia de los Estados Unidos de América en el Acta de Independencia del Alto Perú, cit. (n. 12), VI, pp. 3-5.

${ }^{26}$ Mendoza Loza, Gunnar, cit. (n. 25), p. 8.

${ }^{27}$ Ibíd., p. 6.
} 
the opinions of man kind requires that they should declare the causes which impel them to the separation', equivalente al pasaje altoperuano que expresa, al proclamar este mismo derecho: "creemos llenar nuestro derecho de respeto a las naciones extranjeras, y de información consiguiente, de las razones poderosas y justos fundamentos impulsores de nuestra conducta". La coincidencia se va precisando mayormente en presencia de cláusulas como las siguientes: "When, in the course of human events it becomes necessary for one people to dissolve the political bands which have connected them with another". "Cuando, pues, nos llega la vez de declarar nuestra independencia [...] y decretar nuestro futuro destino", etc. Hay en las dos expresiones, por el simple pero sugerente uso de la partícula "when”, "cuando", presidiendo dos períodos que expresan la misma idea, un neto ambiente de identidad. Las analogías cobran aún más cuerpo cuando las colonias norteamericanas "solemnly publish and declare [...] that they are absolved from all allegiance to the British Crown", al paso que las provincias altoperuanas "declaran solemnemente" que cesa su condición de colonia de España "junto con toda dependencia, tanto de ella como de su actual y posteriores monarcas". Los norteamericanos hacen esta declaración "appealing to the Supreme Judge of the world for the rectitude of our intentions", y los altoperuanos por su parte la hacen "habiendo implorado [...] la paternal asistencia del Hacedor Santo del Orbe [...[ despojándose...de todo espíritu de parcialidad, interés y miras privadas". Los legisladores norteamericanos: "for the support of this declaration, with a firm reliance on the protection of Divine Providence, we mutually pledge to each other our lives, our fortunes, and our sacred honor". Las provincias del Alto Perú, "para la invariabilidad y firmeza de esta resolución se ligan, vinculan y comprometen por medio de esta representación soberana, a sostenerla tan firme, constante y heroicamente que en caso necesario sean consagrados con placer a su cumplimiento, defensa e inalterabilidad, la vida misma, con los haberes y cuanto hay más de caro en el hombre". La relación se hace obvia cuando el texto norteamericano denuncia que el rey de Gran Bretaña ha enviado a América enjambres oficiales "to harass our people, and eat out their substance", y el texto altoperuano proclama por su parte que España "ha despedazado el desgraciado cuerpo de América y nutrídose con su substancia”. Esta final identidad literal tiene el valor de toda una clave para mostrar cómo las identidades y semejanzas que hemos señalado no son meramente casuales o causales sino que un texto ha influido en el otro" 28 .

A su prueba intelectual, Mendoza añadió una "prueba material” que, dijo, le permitía "presentar al autor del acta de independencia altoperuano prácticamente con un ejemplar de la declaración de independencia norteamericana en la mano"29. El Acta de Independencia fue redactada por José Mariano Serrano, que presidía la Asamblea General del Alto Perú, y fue aprobada el 6 de agosto de 1825. Días antes había aparecido en la Gaceta de Chuquisaca una invitación general a una "suscripción voluntaria en volúmenes o en dinero", para dar nacimiento a la primera biblioteca pública del país, que luego devendría en la Biblioteca Nacional

\footnotetext{
${ }^{28}$ Ibíd., pp. 5 y 6.

${ }^{29}$ Ibíd., p. 6.
} 
de Bolivia. La misma gaceta publicó en septiembre del mismo año un listado de "Señores suscriptores de la Biblioteca pública", y a la cabeza figura el "excelentísimo señor Presidente de la Asamblea General, doctor don José Mariano Serrano", con "una obra intitulada Actas y resoluciones de los Congresos de Norte América desde el primero, nueve tomos pasta" ${ }^{30}$. Cuenta Mendoza que la biblioteca pública no nació de ese primer intento, ocasionando que los libros fuesen devueltos a sus donantes. En 1828 se hizo un segundo intento y, "dando salida quizá a algún rencorcillo propio del medio y del momento" ${ }^{31}$, se reclamó coactivamente la obra a su propietario. Así lo dice el propio Serrano, en una nota manuscrita de su puño y letra que Mendoza encontró en la portada del volumen I: "Esta obra fue del Dr. José Mariano Serrano, quien la regaló a la Biblioteca de esta capital, con algunas otras, pero no mereció siquiera un gracias del gobierno, y lejos de eso el señor Prefecto puso una providencia para recogerla de su poder y se mandó al efecto un comisario con un gendarme, tal vez ignorando la circunstancia referida. Pero de todos modos, este fue el fruto del regalo" 32 .

El grado de conocimiento del inglés por parte de Serrano es, según Mendoza, un "problema marginal". El solo hecho de haber tenido la obra dicha en su biblioteca le sugiere que tenía algún dominio de esa lengua: "es lícito afirmar que este libro fue la fuente de inspiración donde el autor del acta de independencia del Alto Perú recogió la influencia de la declaración de independencia norteamericana sobre la altoperuana"33.

De la influencia de la Revolución Americana da cuenta también el gobernador de Cochabamba, José González Prada, en su "Oficio muy reservado" de 30 de diciembre de 1809 a Vicente Nieto, presidente de la Audiencia. Allí dice que es necesario "arrancar de este continente quanto pueda faborecer las ideas de los muchos que han trabajado, y no dejan de delinear el Plan de independencia”, "[porque] han llegado han imbuirse de bariar de constitución, que el suceso de los anglo-americanos les ha dado aliento, y les parece fácil imitar y conseguir" ${ }^{2}$.

\section{VII.}

El de José Mariano Serrano no era un caso atípico. Aunque está claro que el pensamiento revolucionario se formó en el claustro universitario, bajo el manto sacro del naturalismo teológico, los doctores de Charcas, seguidores de Santo Tomás y de Francisco Suárez, en donde supieron del derecho de resistencia al poder tiránico, tuvieron acceso a bibliografía liberal americana y francesa que, llegado el tiempo de poner a andar la república, pudo haber sido abrevadero directo de los noveles políticos.

Se sabe que en la biblioteca particular del deán de Charcas, Matías Terrazas, gracias a su posición que lo eximía de evitar la lista de los libros prohibidos por

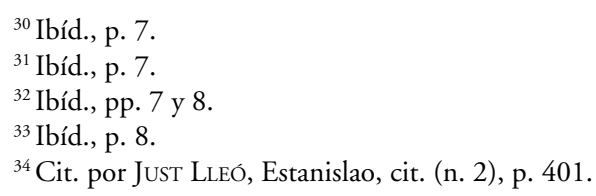


la Inquisición, estaban Rousseau y Montesquieu, y que ella estuvo a disposición de líderes emancipadores como Mariano Moreno ${ }^{35}$, quien vivió en su casa varios meses. Y se afirma que los jóvenes universitarios chuquisaqueños "ya a escondidas leían con fruición las obras de Montesquieu, Raynal, Locke, Rousseau, etc.”36, y que en "las bibliotecas de los intelectuales de Charcas [...] no deja[ba]n de faltar obras, no ya solamente de autores enciclopedistas, o filósofos de la razón -Diderot, Mirabeau, Rousseau-, sino que trata[se]n directamente de los sucesos de la revolución francesa, e incluso algunas manuscritas" ${ }^{37}$. Pero dice Thibaud que no hay en las bibliotecas registro alguno de las obras de Rousseau, Diderot, Voltaire o Montesquieu, aunque tal "extraña ausencia [...] en los informes oficiales puede explicarse por el cuidado que tenían los propietarios de esos libros para esconderlos y evitar que esas obras proscritas figuren en los inventarios" 38 . Esto es verosímil. Ya lo decía Manuel Moreno en 1836: "Todos los mejores autores de Europa, sobre politica, moral, religión, historia, etc., que han pasado de quando en quando por entre las severas prohibiciones del despotismo inquisitorial hasta Buenos Ayres, han ido regularmente a parar al Perú [Alto Perú], donde encuentran mejor recepción [...] porque el espionaje es menos severo, siendo los que están encargados de estorbar la circulación de semejantes obras los mismos que las solicitan y colocan con preferencia en sus estantes" 39 .

Se sabe también que Vicente Pazos Kanki, bajo el seudónimo de Anselmo Natien, tradujo al español el Common Sense de Paine, cuyo original está en la Biblioteca Nacional de Bolivia con el título de Reflexiones políticas escritas bajo el titulo de Instinto Común por el ciudadano Tomás Payne y traducidas abreviadamente por Anselmo Natien, indigena del Perú. Impreso en Londres por cuenta de su mismo traductor $^{40}$. El mismo Pazos Kanki publicó en París, en 1825, su Compendio de la historia de los Estados Unidos de América, en 422 páginas $^{41}$. Y fue este mismo desde Buenos Aires, en su Breve observación de los documentos publicados en el No. 55 de El Censor, quien respondió, en el número de la Crónica Argentina de 22 de septiembre de 1816, a las proclamas de Belgrano y Güemes exponiendo sus ideas monárquicas tendientes a la restauración incaica, aparecidas el 12 de septiembre de 1816. Allí se refirió al "floreciente gobierno del Norte de América", en el que se ve "una democracia sin desorden, y no es tan fácil presentar aristocracias sin insolencia, ni monarquías (aún constitucionales, si es que hay o puede haber alguna más que la de Inglaterra) sin tirania y sin usurpación". Y se preguntaba: “iNos proporcionaría [el restablecimiento de la casa de los Incas] algunas ventajas

${ }^{35}$ Mendoza Loza, Gunnar, cit. (n. 25), p. 9.

${ }^{36}$ Just Lleó, Estanislao, cit. (n. 2(, p. 340.

${ }^{37}$ Ibíd., p. 398.

${ }^{38}$ Thibaud, Clément, La Academia Carolina y la independencia de América (Sucre, Charcas/ Fundación Cultural del Banco Central de Bolivia/Archivo y Biblioteca Nacionales de Bolivia, 2010), p. 73.

${ }^{39}$ Cit. por Thibaud, C., cit. (n. 38), p. 61.

${ }^{40}$ Arnade, Charles W., La dramática insurgencia de Bolivia (La Paz, Juventud), pp. 19 y 299.

${ }^{41}$ Arnade, Charles W., cit. (n. 40). 
mayores que las que lograremos gobernados, por ejemplo, por un sistema como de la América del Norte?" 42.

Es muy cierto que el de Pazos Kanki fue un caso excepcional. Nacido en La Paz, estudió teología en el Cuzco, se doctoró en 1804 y en 1806 fue ordenado sacerdote. En Buenos Aires tomó parte activa en la política, editando dos periódicos de importancia para el pensamiento independentista, La Gaceta y El Censor. Se fue exiliado a la Gran Bretaña. En 1816 retornó a Buenos Aires y editó La Crónica Argentina. Una segunda vez fue exiliado, esta vez a Estados Unidos, y allí fue parte de un "intento frustrado de expulsar a los españoles de la Florida" ${ }^{43}$. Pero conoció a Montesquieu, Mirabeau, Locke, Raynal, Smith y Voltaire en el mismo lugar que tradujo a Paine: en Chuquisaca ${ }^{44}$. Por tanto, así como él, otras mentes de la emancipación pudieron también formarse en las doctrinas liberales acudiendo directamente a sus fuentes clásicas, como fueron los casos de Moreno y Serrano. La mención, por ejemplo, a "nuestra primitiva libertad", dicha en la proclama de la Junta tuitiva de los derechos del Rey y del Pueblo de La Paz, patentiza que sus redactores conocían el lenguaje del contractualismo liberal.

Ya llegada la república, la influencia francesa se hizo incluso oficial: el decreto reglamentario de 28 de octubre de 1827 prescribía que "el Derecho Público se enseñará por ahora por Benjamin Constant, mientras haya otra obra elemental más acomodada a la forma de Gobierno, adoptada en la República. La Constitución y las leyes orgánicas se estudiarán en su texto original'"45 (artículo 134).

\section{VIII.}

El texto original de la Constitución lo redactó Bolívar de su puño y letra, viene de 1826, año de su aprobación. Por fuente documental se tiene, además del texto de la Constitución, el "Mensaje de Bolívar al Congreso Constituyente de Bolivia". Allí no hay mención, ni tangencial siquiera, a España ni a Cádiz. Pero si hubo alguna influencia debe buscársela en las analogías que "no aluden a situaciones generales semejantes", para seguir el método de Mendoza que, por cuestión de coherencia, estoy obligado a seguir al haber aceptado sus conclusiones respecto a la influencia de la Declaración de Independencia de Estados Unidos en el Acta de Independencia del Alto Perú.

En su mensaje, Bolívar destaca cuatro aspectos distintivos de la Constitución de 1826, que le darían su originalidad: i) La constitución de un cuarto poder, el electoral; ii) una presidencia vitalicia; iii) la organización de un legislativo de tres cámaras, de tribunos, senadores y censores; y iv) la elección popular de los precandidatos a jueces.

Comenzando por el último, quería Bolívar con tal mecanismo de preselección

\footnotetext{
${ }^{42}$ Pazos Kanki, Vicente, Breve observación de los documentos publicados en el No 55 de El Censor, en Oblitas Fernández, Edgar, La polémica en Bolivia (La Paz, Temis, 1997), I, pp. 175 y 177.

${ }^{43}$ Arnade, Charles W., cit. (n. 5), II, p. 499.

${ }^{44}$ Obltas Fernández, Edgar, cit. (n. 42), p. 157.

${ }^{45}$ Cit. por Trigo, C. F., cit. (n. 19), p. 38.
} 
garantizar la independencia de los jueces de la república: "El poder judicial que propongo goza de una independencia absoluta: en ninguna parte tiene tanta. El pueblo presenta los candidatos, y el legislativo escoge los individuos que han de componer los tribunales. Si el poder judicial no emana de este origen, es imposible que se conserve en toda su pureza la salvaguardia de los derechos individuales. Estos derechos, legisladores, son los que constituyen la libertad, la igualdad, la seguridad, todas las garantías del orden social. La verdadera constitución liberal está en los códigos civiles y criminales; y la más terrible tiranía la ejercen los tribunales por el tremendo instrumento de las leyes" ${ }^{36}$. Su motivación queda clara del párrafo trascrito. Sobre este tema no confiesa influencia normativa alguna, moderna o antigua.

Respecto a las tres cámaras legislativas, quiso con ellas dar equilibrio interno al órgano. "El cuerpo legislativo tiene una composición que lo hace necesariamente armonioso entre sus partes: no se hallará siempre dividido por falta de un juez árbitro, como sucede donde no hay más que dos cámaras. Habiendo aqui tres, la discordia entre dos queda resuelta por la tercera; y la cuestión examinada por dos partes contendientes y una imparcial que la juzga: de este modo ninguna ley útil queda sin efecto, o por lo menos, habrá sido vista, una, dos y tres veces, antes de sufrir la negativa”. Y respecto a las competencias de cada cámara, las de los censores son las destacables a estos efectos: "Los censores ejercen una potestad politica y moral que tiene alguna semejanza con la del areópago de Atenas, y de los censores de Roma". Añadía: "Son los censores los que protegen la moral, las ciencias, las artes, la instrucción y la imprenta". Así como en este punto reconoce expresamente haberse inspirado, en lo que cabe, en el pasado helénico y romano, también, en lo que respecta a las tres cámaras, reconoce expresamente su afán de no seguir el modelo bicameral ni el monocameral: "Los congresos modernos, me dirán, se han compuesto de solas dos secciones. Es porque Inglaterra, que ha servido de modelo, la nobleza y el pueblo debian representarse en dos cámaras; y si, en Norte América se hizo lo mismo sin haber nobleza, puede suponerse que la costumbre de estar bajo el gobierno inglés le inspiró esta imitación. El hecho es que dos cuerpos deliberantes deben combatir perpetuamente; y por esto Sieyes no quería más que uno. Clásico absurdo" ${ }^{47}$.

Hasta aquí Cádiz no aparece como fuente de inspiración. Y aunque la presidencia vitalicia de la Constitución de 1826 podría delatar parentescos con una monarquía constitucional como la que Cádiz quería instaurar, lo cierto es que acusar tal vínculo sería apresurado: $i$ ) Porque de la cita anterior ya queda dicho que Bolívar conocía el sistema constitucional británico, así que antes de fijarse en el intento que dio la Constitución de 1812, se habría fijado, más bien, en aquel, que fue la fuente primera; ii) Porque, con todo lo contradictorio del lenguaje, la presidencia vitalicia se inspiró en modelos republicanos. Mírese que toma el modelo, según su entender, de Haití y Estados Unidos: "El presidente de Bolivia participa de las facultades del ejecutivo americano, pero con restricciones favorables a su pueblo. Su duración es la de los presidentes de Haití. Yo he tomado para Bolivia el ejecutivo de la República más democrática del mundo. La isla de Haití (permitaseme

\footnotetext{
${ }^{46}$ Ibíd., p. 194.

${ }^{47}$ Ibíd., pp. 190 y 191.
} 
esta digresión) se hallaba en insurrección permanente: después de haber experimentado el imperio, el reino, la república, todos los gobiernos conocidos y algunos más, se vio forzada a ocurrir al ilustre Petión para que la salvase. Confiaron en él, y los destinos de Haití no vacilaron más. Nombrado Petión presidente vitalicio con facultades para elegir el sucesor, ni la muerte de este grande hombre, ni la sucesión del nuevo presidente, han causado el menor peligro en el estado: todo ha marchado bajo el digno Boyer, en la calma de un reino legitimo. Prueba triunfante de que un presidente vitalicio, con derecho para elegir el sucesor, es la inspiración más sublime en el orden republicano. El presidente de Bolivia será menos peligroso que el de Haití, siendo el modo de sucesión más seguro para el bien del estado. [...]. En el gobierno de los Estados Unidos se ha observado últimamente la práctica de nombrar al primer ministro para suceder al presidente. Nada es tan conveniente, en una república, como este método; reúne la ventaja de poner a la cabeza de la administración un sujeto experimentado en el manejo del estado. Cuando entra a ejercer sus funciones, va formando y lleva consigo la aureola de la popularidad, y una práctica consumada. Me he apoderado de esta idea y la he establecido como ley. El presidente de la república nombra al vicepresidente, para que administre el estado y le suceda en el mando" ${ }^{48}$. Puede acusarse que el modelo propuesto llevaría al despropósito, que él cita como mérito en Haití, de fundar un gobierno de poderes limitados en la templanza de la persona del presidente, y no en la constitución republicana. Y puede también acusársele de una apreciación errónea del sistema constitucional americano. Ya de esto dio indicios cuando creyó que el bicameralismo estadounidense se fundaba en la herencia inglesa (citado en lo referente a las tres cámaras legislativas), cuando su fundamento no es la división de clases, sino de territorios, el federal y los estaduales. Pero queda dicho que no estaba proyectando, a su entender, una monarquía constitucional. Esto excluye alguna influencia de Cádiz en la presidencia vitalicia.

Queda el tema del poder electoral. Ya la Constitución de Cádiz había dedicado buena parte de su articulado al tratamiento minucioso de las juntas electorales de parroquia, de partido y de provincia (artículos 34 a 103), que debían celebrarse para la "elección de los Diputados de Córtes" (artículo 34). Por su parte, en la Constitución de 1826 el poder electoral lo ejercían "inmediatamente los ciudadanos en ejercicio, nombrando por cada ciento un elector” (artículo 20), y estos electores, a su turno, formaban el cuerpo electoral (artículo 23). Hay dos argumentos para negar que las juntas electorales de Cádiz fueran inspiración del poder electoral: $i$ ) A pesar de su identidad como mecanismos de elección, el poder electoral pretendió ser, por definición, un órgano constituido. De ahí que mientras las juntas se celebraban para la elección de diputados y allí agotaban sus funciones, al cuerpo electoral correspondía una verdadera asignación de competencias (artículo 26). La entidad de ambos conceptos era, pues, distinta; ii) En lo que el poder electoral y las juntas de Cádiz comparten identidad en tanto que mecanismos de elección, el uso de la palabra federal en el propio dicho de Bolívar permite conjeturar que se habría fijado en Estados Unidos: "El proyecto de constitución para Bolivia está dividido en cuatro poderes políticos, habiendo añadido uno más, sin complicar por

${ }^{48}$ Ibíd., pp. 192 y 194. 
esto la división clásica de cada uno de los otros. El electoral ha recibido facultades que no le estaban señaladas en otros gobiernos que se estiman entre los más liberales. Estas atribuciones se acercan en gran manera a las del sistema federal. Me ha parecido no sólo conveniente y útil, sino también fácil, conceder a los representantes inmediatos del pueblo los privilegios que más pueden desear los ciudadanos de cada departamento, provincia y cantón. Ningún objeto es más importante a un ciudadano que la elección de sus legisladores, magistrados, jueces y pastores. Los colegios electorales de cada provincia representan las necesidades y los intereses de ellas, y sirven para quejarse de las infracciones de las leyes y de los abusos de los magistrados. Me atrevería a decir con alguna exactitud que esta representación participa de los derechos de que gozan los gobiernos particulares de los estados federales" ${ }^{49}$. Las dos referencias al federalismo llevan a pensar en el colegio electoral creado por la Constitución de los Estados Unidos de 1787. En tiempos de Bolívar la única federación moderna era la americana. De hecho, fue la Convención de Filadelfia la que innovó el término, que hasta ese momento significaba confederación (era el pactus foedis de la antigüedad). Sólo podría estar refiriéndose a aquella, porque ni en la antigüedad ni en los días de hoy la ciudadanía elije a los representantes de una confederación, y lo que él buscaba era, más bien, acercar al ciudadano a sus representantes. Sin embargo, Pierangelo Catalano opina que la superación del "modelo tripartito de Montesquieu" se produce en Bolívar por su inspiración rousseaniana ${ }^{50}$. Lo mismo, Carlos Gonzalo de Saavedra afirma, sin más, que su Constitución fue hecha "con el recuerdo puesto en los lejanos días de la Francia revolucionaria que necesitaba salvarse entregándose a directores y tribunos" ${ }^{51}$. Cabe que el federalismo americano le haya servido a Bolívar de instrumento para materializar su influencia doctrinaria, o de remedio para prevenir que la naciente república corriese la suerte de la instaurada por la Revolución de 1789. Sería algo tan normal como que en tanto hecho social el derecho es un epifenómeno de la cultura y, por tanto, reactivo a sus necesidades. Pero, con todo, la influencia de Cádiz sigue quedando fuera.

IX.

La otra fuente documental es la propia Constitución de 1826. Hay en ella ciertas coincidencias con la Constitución de Cádiz que denotan el conocimiento de su texto. Así, mientras en Cádiz se decía que "La Nación española es la reunión de todos los españoles de ambos hemisferios" (artículo 1), en Bolivia se dijo: "La Nación boliviana es la reunión de todos los bolivianos" (también artículo 1). Lo mismo, el artículo 2 de la Constitución de Cádiz decía que "La Nación española es libre é independiente, $y$ no es ni puede ser patrimonio de ninguna familia ni persona”, y el artículo 2 de la Constitución de Bolivia expresa: "Bolivia es, y será para siempre, independiente de toda dominación extranjera; y no puede ser patrimonio de ninguna

\footnotetext{
${ }^{49}$ Ibíd., p. 190.

${ }^{50}$ Catalano, Pierangelo, Principios constitucionales bolivarianos: origen y actualidad, en $E l$ nuevo Derecho Constitucional latinoamericano, 2 (1996), p. 547.

${ }^{51}$ De SaAvedra, Carlos Gonzalo, El Deán Funes y la creación de Bolivia (La Paz, Los Amigos del Libro, 1972), p. 35.
} 
persona ni familia". Y en ambos paises, por ley, se haria la "división más conveniente" del territorio (artículo 11 en España y 5 en Bolivia).

También en ambos casos el acceso a la justicia dependía del agotamiento previo de la conciliación: "Sin hacer constar que se ha intentado el medio de la conciliación no se entablará pleyto alguno" (artículo 284 de la Constitución de Cádiz), y "Habrá jueces de paz en cada pueblo para las conciliaciones; no debiéndose admitir demanda alguna civil o criminal de injurias, sin este previo requisito" (artículo 117 de la Constitución de Bolivia). Y en lo que hace a las garantías del debido proceso, "Ningún español podrá ser preso sin que preceda información del hecho por el que merezca según la ley ser castigado con pena corporal, y asimismo un mandamiento del juez por escrito, que se le notificará en el acto mismo de la prisión" (artículo 287), y "Ningún boliviano puede ser preso, sin precedente información del hecho, por el que merezca pena corporal, y un mandamiento escrito del juez ante quien ha de ser presentado" (artículo 122). Y el texto común de los artículos 292 de la Constitución española y 124 de la boliviana, decía: "En fraganti todo delincuente puede ser arrestado" para conducirlo a la "presencia del juez". Y: "No se usará del tormento ni de los apremios", ni "Tampoco se impondrá la pena de confiscación de bienes" (artículos 303 y 304 de la Constitución de Cádiz), y en Bolivia: "No se usará jamás del tormento, ni se exigirá confesión por apremio", y: "Queda abolida toda confiscación de bienes, $y$ toda pena cruel y de infamia trascendental" (artículos 126 y 127), al igual que en España "Ninguna pena que se imponga, [...] ha de ser trascendental por término ninguno á la familia del que la sufre, sino que tendrá todo su efecto precisamente sobre el que la mereció" (artículo 305).

Finalmente, en materia tributaria: "Las contribuciones se repartirán entre todos los españoles con proporción á sus facultades, sin excepciones ni privilegio alguno" (artículo 339), y en Bolivia: "Las contribuciones se repartirán proporcionalmente, sin ninguna excepción ni privilegio" (artículo 153).

Ninguna de estas va más allá de ser una semejanza de redacción. Que es muy probable que ellas fueran deliberadas, es un hecho. Esto se intuye sobre todo en las menciones a "ningún español" (artículo 287) y a "ningún boliviano" (artículo 122). En ambos casos pudo decirse "nadie". No haber usado este pronombre en la Constitución de Bolivia sugiere que se tomó el texto español tal cual y se cambio sólo lo referente a la nacionalidad. Lo mismo respecto al latinazgo "in fraganti", que pudo ser reemplazado por su versión castiza "flagrante". Y también respecto al texto del artículo 127 de la Constitución de 1826, que abruptamente termina con las palabras "infamia trascendental", lo que sugiere que su texto hubiese resultado de, a la vez, una fusión de los artículos 304 y 305 de la Constitución de Cádiz y un cercenamiento de este último, obscureciendo el texto que en su versión original era claro.

Nótese que todas las coincidencias textuales se refieren a cuestiones comunes a cualquier constitución liberal (el concepto de nación y garantías procesales y tributarias), y no a aspectos distintivos u originales aparecidos en Cádiz. De todos los indicios que se llevan dichos, si alguno habría a favor de afirmar una influencia de Cádiz en Charcas, sería tan sólo este recuento de coincidencias textuales. Y este indicio es menos convincente que los otros, que llevan a negar tal influencia. 
Si hay una constante en los últimos días coloniales, ella está constituida precisamente por los afanes de la independencia. Esto habría desembocado en que se viese a las Cortes de Cádiz y su Constitución como un acto de conquista en el pleno sentido de la expresión: una pretensión foránea enemiga de la pretensión independentista que mantenía al continente en pie de lucha. En este contexto, no creo que las coincidencias fraseológicas revelen una influencia, en el sentido de reconocimiento de valores que merecen ser emulados, sino la satisfacción de una necesidad práctica inmediata. Acá hace perfecto sentido la coincidencia en el idioma de ambas constituciones. Mientras Bolívar pudo muy bien encontrar sus ideas en Estados Unidos, Haití, Atenas y Roma, o Rousseau, también pudo tomar la redacción de España en todo lo que fuese general al modelo liberal. No hay el esfuerzo de traducir un texto y tomar de él su vigor argumentativo, que es lo que sí hubo entre la Declaración de Independencia de Estados Unidos y el Acta de Independencia del Alto Perú. Lo que hubo entre la Constitución de Cádiz y la de Bolivia de 1826 fue un auxilio técnico: el de ofrecer un fraseo en español para ciertas consecuencias normativas específicas de un modelo político ya abrazado de antemano. Si Cádiz no hubiese ocurrido, Bolivia por igual hubiese tenido su Constitución de 1826. Era el hado de los tiempos. La influencia en Charcas debe buscársela en la irresistible fuerza del pensamiento liberal. Que España haya tenido un momento liberal en el último tramo de la colonia, no significa que haya formado en los independentistas la convicción de decantarse por el liberalismo. Significa que tampoco ella pudo resistirse al empuje del pensamiento liberal.

\section{BiBLIOGRAFÍA}

Arnade, Charles W., La dramática insurgencia de Bolivia (La Paz, Juventud).

Barnadas, Joseph M. para el Diccionario histórico de Bolivia (Sucre, Grupo de Estudios Históricos, 2002), I.

Catalano, Pierangelo, Principios constitucionales bolivarianos: origen y actualidad, en El nuevo Derecho Constitucional latinoamericano, 2 (1996).

De SaAvedra, Carlos Gonzalo, El Deán Funes y la creación de Bolivia (La Paz, Los Amigos del Libro, 1972).

Itinerario documental de Simón Bolivar, Escritos selectos (Caracas, Ediciones de la Presidencia, 1970).

Just Lleó, Estanislao, Comienzo de la independencia en el Alto Perú. Los sucesos de Chuquisaca, 1809 (Sucre, Editorial Judicial, 1994).

Mendoza Loza, Gunnar, Influencia de la Declaración de Independencia de los Estados Unidos de América en el Acta de Independencia del Alto Perú, en Obras Completas (Sucre, Fundación Cultural del Banco Central de Bolivia/Archivo y Biblioteca Nacionales de Bolivia, 2005), VI.

Mendoza Loza, Gunnar, Monografia de Chuquisaca: historia colonial, historia de la independencia, cultura, en Obras Completas (Sucre, Fundación Cultural del Banco Central de Bolivia/Archivo y Biblioteca Nacionales de Bolivia, 2005), I.

Moreno, Gabriel René, Últimos días coloniales en el Alto Perú (La Paz, Juventud).

Pazos Kanki, Vicente, Breve observación de los documentos publicados en el No 55 de 
El Censor, en Oblitas Fernández, Edgar, La polémica en Bolivia (La Paz, Temis, 1997), I.

Pérez Fernández, Marcelino, Pensadores cruceños (Santa Cruz, UPSA, 1992).

Siles Salinas, Jorge, Historia de la Independencia de Bolivia (2a edición, La Paz, Plural, 2009).

Thibaud, Clément, La Academia Carolina y la independencia de América (Sucre, Charcas/Fundación Cultural del Banco Central de Bolivia/Archivo y Biblioteca Nacionales de Bolivia, 2010).

Tredinnick Abasto, Felipe, La revolucionaria Constitución de Cádiz de 1812, en Revista del Tribunal Constitucional, 3 (2000).

Trigo, Ciro Félix, Las constituciones de Bolivia (2a edición, La Paz, Fondo Editorial de la Biblioteca y Archivo Histórico del Honorable Congreso Nacional, 2003).

VázQuez Machicado, Humberto, El Pasquismo sedicioso y los prodromos de la emancipación en el Alto Perú, en Completas (La Paz, Don Bosco, 1988), III.

VÁzQuez Machicado, Humberto, Evolución de las ideas y los partidos políticos en Bolivia, en Obras Completas (La Paz, Don Bosco, 1988), VII. 
